\title{
CAPABILITIES OF REMOTE SENSING HYPERSPECTRAL IMAGES FOR THE DETECTION OF LEAD CONTAMINATION: A REVIEW
}

\author{
Ali Al Maliki ${ }^{{ }^{*}}$, Gary Owens ${ }^{\mathrm{a}}$, David Bruce ${ }^{\mathrm{b}}$ \\ ${ }^{a}$ Centre for Environmental Remediation and Risk Assessment (CERAR). University of South Australia, Mawson Lakes \\ Campus GPO Box 2471, Adelaide SA 5001 Australia (alyay004, Gary.Owens)@unisa.edu.au \\ ${ }^{\mathrm{b}}$ School of Natural and Built Environments, Barbara Hardy Institute, University of South Australia, Mawson Lakes \\ Campus GPO Box 2471, Adelaide SA 5001 Australia David.Bruce@unisa.edu.au
}

\section{Commission VII, WG VII/3}

KEYWORDS: Remote sensing, lead pollution, hyperspectral images, soil properties, visible near-infrared reflectance.

\begin{abstract}
:
Advances in remote sensing technologies are increasingly becoming more useful for resource, ecosystem and agricultural management applications to the extent that these techniques can now also be applied for monitoring of soil contamination and human health risk assessment. While, extensive previous studies have shown that Visible and Near Infrared Spectroscopy (VNIRS) in the spectral range 400-2500 $\mathrm{nm}$ can be used to quantify various soil constituents simultaneously, the direct determination of metal concentrations by remote sensing and reflectance spectroscopy is not as well examined as other soil parameters. The application of VNIRS, including laboratory hyperpectral measurements, field spectrometer measurements or image spectroscopy, generally achieves a good prediction of metal concentrations when compared to traditional wet chemical methods and has the advantage of being relatively less expensive and faster, allowing chemical assessment of contamination in close to real time. Furthermore, imaging spectroscopy can potentially provide significantly more samples over a larger spatial extent than traditional ground sampling methods. Thus the development of remote sensing techniques (field based and either airborne or satellite hyperspectral imaging) can support the monitoring and efficient mapping of metal contamination (in dust and soil) for environmental and health impact assessment. This review is concerned with the application of remote sensing and reflectance spectroscopy to the detection of heavy metals and discusses how current methods could be applied for the quantification of $\mathrm{Pb}$ contaminated soil surrounding mines and smelters.
\end{abstract}

\section{INTRODUCTION}

Hyperspectral images provide rich spectral, and generally spatially continuous information, that can be used for determining more detailed spectral properties of the soil surface and mineralogy, which can in turn be applied for mapping and monitoring soil contamination. Depending on the material's spectral response, reflectance spectroscopy is also relatively less expensive and faster than traditional wet chemical measurements (Summers, 2009). Visible, Near and Short Wave Infrared Spectroscopy (VNIR-SWIR) in the spectral range 400$2500 \mathrm{~nm}$, can be used to quantify various soil constituents simultaneously due to the presence of strong spectral features attributable to soil components in this region (Wu et al., 2005a; Ben-Dor et al., 2009; Minasny et al., 2009). However, it is commonly accepted that inorganic material such as heavy metals, which do not display characteristic absorption/reflection features, cannot be directly detected in the VNIR-SWIR region (Winkelmann, 2005; Wu et al., 2005b). However, while some recent studies have suggested that heavy metals such as $\mathrm{Pb}$ can be directly detected (Zhang et al., 2010), other studies have suggested that heavy metals can only be detected indirectly via their affect on other soil constituents, such as organic matter, iron oxides or clay minerals, which do have detectable spectral features in this region (Choe et al., 2008; Vohland et al., 2009; Pandit et al., 2010; Zhang et al., 2010; Schwartz et al., 2011; Yaolin et al., 2011). Variations in these spectral features occurs as a result of differences in surface activity which results in enrichment of cations in the mineral phase and consequential influence on the spectral signal of heavy metals when bound to

*Corresponding author. other minerals (Schwartz et al., 2011). In order to accurately predict soil contamination via a spectral signal it is first necessary to understand the relationships between spectrally active constituents, which have direct and significant impact on the reflectance of heavy or trace metals (Wu et al., 2005b; Rossel et al., 2006; Wu et al., 2007; Minasny et al., 2009). This review is concerned with the application of remote sensing and reflectance spectroscopy to the detection of heavy metals and discusses how current methods could be applied for the quantification of $\mathrm{Pb}$ contaminated soil surrounding mines and smelters.

\section{INDUSTRIAL EMISSIONS OF PB FROM MINING} AND SMELTERS AREAS

The continuous emission and accumulation of Lead $(\mathrm{Pb})$ as a result of rapid industrialization and urbanization has caused serious problems for the environment and for food security (Zhang et al., 2010). Lead is found in a variety of forms at various concentrations in soil, rocks, plants, and even within human or animal bodies. Pure $\mathrm{Pb}$ is rare in nature and is usually found as an ore in association with other metals such as zinc, silver and copper. Most environmental $\mathrm{Pb}$ concentrations result from human activities which are detrimental to organisms and human health (Griffith, 2002; Wu et al., 2007). Although, there are various sources and pathways associated with $\mathrm{Pb}$ contamination, metal emissions from mining, smelters and the associated industrial processes including manufacturing are believed to be a significant cause of soil and plant contamination in areas surrounding industrial regions (Table 1). Concentration of $\mathrm{Pb}$ in dust and soil is considered to be a worldwide issue which poses a potential risk to human health, 
particularly to children, as well as impairment of soil function (Kachenko and Singh, 2006; WHO, 2010).

\begin{tabular}{|c|c|c|c|c|}
\hline sample & study location & Source & Exposure level & References \\
\hline \\
\hline Biological & Jamaica & lead smelter & $\begin{array}{l}44 \% \text { child under } 6 \text { year of age } \\
\text { have } \mathrm{PbB} \geq 25 \mathrm{mg} / \mathrm{dl}\end{array}$ & Tong et al (2000) \\
\hline Biological & China & $\begin{array}{l}\text { industrial areas } \\
\text { and heavy traffic }\end{array}$ & $\begin{array}{l}\text { Children have PbB } \\
21.8-67.9 \mathrm{mg} / \mathrm{dl}\end{array}$ & Tong et al (2000) \\
\hline Biological & India & leaded petrol & $\begin{array}{l}51 \% \text { child and adults have } \\
\mathrm{PbB}>10 \text { and } 13 \% \text { child and } \\
\text { adults have } \mathrm{PbB}>20 \text { mg/dl }\end{array}$ & Tong et al (2000) \\
\hline Biological & Mexico & $\begin{array}{l}\text { leaded petrol } \\
\text { pica behavior }\end{array}$ & $\begin{array}{c}\text { Child }<5 \text { years of age have } \mathrm{PbB} \\
1-31 \text { and } 44 \% \geq 18 \text { months }> \\
10 \mathrm{mg} / \mathrm{dl}\end{array}$ & Tong et al (2000) \\
\hline Biological & Mexico & 3 smelters & $\begin{array}{l}\text { Women have blood and } \\
\text { milk } \mathrm{Pb}=45.88 \mathrm{mg} / \mathrm{dl}\end{array}$ & Namihiraet al (1993) \\
\hline \multicolumn{5}{|l|}{ Australia } \\
\hline Biological & $\begin{array}{c}\text { Northem } \\
\text { Lake Macquarie }\end{array}$ & smelter & $\begin{array}{l}\text { Children have PbB } \\
10-42 \mathrm{mg} / \mathrm{dl}\end{array}$ & Gulson et al (2004) \\
\hline Biological & Port Pinie & smelter & $\begin{array}{l}\text { Children have PtB } \\
>10 \mathrm{mg} / \mathrm{dl}\end{array}$ & $\begin{array}{l}\text { McMichael et al } \\
\text { (1994) }\end{array}$ \\
\hline Chemical & Boolaroo & smelter & $\begin{array}{c}>95 \% \text { vegetable have } \mathrm{Pb} \\
>0.01 \mathrm{mg} \mathrm{kg}\end{array}$ & $\begin{array}{l}\text { Kachenko and Singh } \\
(2006)\end{array}$ \\
\hline Chemical & Port Kembla & industrial area & Soil has $\mathrm{Pb}>300 \mathrm{mg} \mathrm{kg}$ & Martley et al (2004) \\
\hline Chemical & Port Pirie & smelter & $\begin{array}{l}7.3 \% \text { child } 1-4 \text { year have } \mathrm{PbB} \geq \\
10 \text { mg/dl and } 1.7 \% \text { child } \\
\text { have } \mathrm{PbB} \geq 15 \mathrm{mg} \text { dl }\end{array}$ & $\begin{array}{l}\text { Lead in Australian } \\
\text { children(1996) }\end{array}$ \\
\hline Chemical & $\begin{array}{l}\text { Boolaroo } \\
\text { Port Kembla }\end{array}$ & $\begin{array}{l}\text { smelter } \\
\text { smelter }\end{array}$ & $\begin{array}{l}\text { Soil has lead }>300 \mathrm{mg} / \mathrm{kg} \\
\text { Soil has lead }>300 \mathrm{mg} / \mathrm{kg}\end{array}$ & $\begin{array}{l}\text { Kachenko and Singh } \\
\text { (2004) }\end{array}$ \\
\hline
\end{tabular}

Table 1 Typical worldwide sources of $\mathrm{Pb}$ contamination which are of health concern.

\section{SPECTRAL REFLECTANCE IN SOIL}

Any useful quantitative remote sensing technique would require a basic knowledge of the spectral characteristics of the remotely sensed materials, where the material's reflectance is a function of surface material absorption, wavelength and emissivity characteristics(Harris, 2006;Schwartz et al.,2011). The diversity of soil absorption processes from reflected or emitted light can provide significant information which can be used to derive mineral composition (Clark, 1999). Remote sensing techniques can only generally detect the thin, upper layer viewed by the optical sensors, so that the reflectance spectra obtained during remote sensing are affected by several factors related to the soil surface properties, including moisture, organic content, mineral composition and the material concentration at the time of data acquisition. Some of the issues currently limiting adoption of remote sensing of metals as a useful analytical are discussed in more detail below.

\subsection{Spectral Mixing}

Previous studies have identified that heavy metals possess spectral indicators in the visible and near-infrared regions which are useful for detecting trace metal concentrations (Kemper and Sommer, 2003; Choe et al., 2008; Ji et al., 2010). However, the quantitative assessment of soil components using reflectance spectra is a challenging problem because the assessment of the sub-pixel abundance of soil materials is complex. In practice most of the extracted pixel spectra would not be exclusively from the metal contaminant, but would be a complex mixture of spectra from various land surface elements (Kemper and Sommer, 2002 ; Garcia-Haro et al., 2005). Thus spectral mixing is an important issue to resolve in any reflectance spectoscopic method. In recent years spectral mixture analysis (SMA) has developed as a widely used process for multi or hyperspectral image processing. The technique is used to identify the subpixel proportions of ground, plants and other materials represented in each pixel, where each of these component was labelled as an "endmember" (EM) (Garcia-Haro et al., 2005). These elements fundamentally contribute to the observable spectral signal of the mixed pixels. SMA decomposes the reflectance spectrum of each pixel to the proportional spectral involvement (Kemper et al., 2000). The way in which various spectra from EMs combine to form a single pixel spectrum is termed a "mixture model". These models are used in the unmixing analysis. A spectral mixture modelling approach was applied to field and airborne hyperspectral data and Variable Multiple Endmember Spectral Mixture Analysis (VMESMA) was used to estimate the quantities and distribution of the remaining tailing material (Schwartz et al., 2011). VMESMA tools are already available that can be used to provide quantitative information about the distribution of residual heavy metal contamination of surface constituents (Kemper et al., 2000; Plaza et al., 2002; Kemper \& Sommer, 2003; Garcia-Haro et al., 2005). SMA permits repeatable and accurate extraction of quantitative subpixel information including physical models of surface processes, when supported by ground data. Therefore SMA offers an efficient mechanism for understanding and classification of multidimensional imagery in remote sensing (Garcia-Haro et al., 2005). Subpixel analysis of an area has recently been made possible due to improvements in sensor spectral resolution and this allows for the quantification of the abundance of different materials within a single pixel using linear spectral unmixing (Plaza et al., 2002 ).

\subsection{Soil Spectroscopy}

Many studies over the last two decades have explored new remote sensing techniques which have utilized the reflected radiation of soils (Wu et al., 2005a; Wu et al., 2007; Ben-Dor et al., 2009; Minasny et al., 2009; Bilgili et al., 2010). As a result of these studies, the reflectance radiation across the VIS-NIR and SWIR in the region between 400-2500 $\mathrm{nm}$ is often considered a useful region with which to predict unknown soil properties. Such techniques are becoming more significant for the cost effective coverage of large areas and can provide chemical information relatively quickly compared to traditional field sampling and subsequent chemical analysis. The spectrally assigned position of minerals can be affected by chemical composition and physical conditions at the surface (Ben-Dor et al., 2009). Previous studies have shown that many soil properties have distinct spectral signatures (Ben-Dor et al., 2002; Kemper and Sommer, 2002; Bray et al., 2009) including cation exchange capacity (CEC) (Fox and Metla, 2005), soil organic matter content (Galvão and Vitorello, 1998; Ben-Dor et al., 2002; Fox \& Metla, 2005), iron content (Fox and Metla, 2005; Pastor et al., 2008), soil electrical conductivity (Shrestha, 2006) These constituents provide another possibility of identifying soil characteristics and assessing soil properties quantitatively using field or laboratory radiometry (Bray et al., 2009; Ji et al., 2010; Yaolin et al., 2011). Kooistra et al. (2001) applied visible-near-infrared spectroscopy to assess soil contamination in river floodplains in the Netherlands and concluded that, in floodplain soils, metal concentrations depended on the exchange capacity of the soil. Soil surveys using VNIR spectra are valuable techniques for identification of several soil properties and can be applied for soil conservation (Pastor et al., 2008). It is therefore clear that remote sensing techniques have the potential to accurately identify soils properties for different environmental and agricultural purposes.

\subsection{High Spectral Soil Components}

Organic matter $(\mathrm{OM})$ has distinctive spectra particularly in the NIR due to formation of covalent bonds with a variety of molecules (Schwartz et al., 2011). Many studies have indicated 
that soil organic matter $(\mathrm{SOM})$ can be accurately predicted using reflectance spectroscopy. For instance; estimation of SOM was more appropriate in the visible region (Krishnan et al., 1980) which was in agreement with, Rossel et al (2006) who also observed that the prediction of soil organic carbon (SOC) was better in the VIS range at 410, 570, $660 \mathrm{~nm}$ where some researchers had reported. a significant correlation between $\mathrm{OM}$ in soil and spectral reflectance in the range 545 $830 \mathrm{~nm}$ (Lu et al., 2007; Yaolin et al., 2011). Some of these studies also indicated that a good correlation between soil properties and spectroscopy occurred when the first-order derivative of spectral reflectance was used (Lu et al., 2007; Yaolin et al., 2011). The number of spectral regions and quantitative predictions of SOM and SOC are reviewed in Table 2. The concentration of SOM is inversely related to reflectance in the VIS and NIR range, especially, when the organic content is more than $2 \%$ (Summers, 2009).

\begin{tabular}{lllll}
\hline Soil OC OR OM (\%) & Spectral region & $\begin{array}{l}\text { Spectral } \\
\text { range(nm) }\end{array}$ & $\mathrm{R}^{2}$ & Authors \\
\hline OM & VIS-NIR & $400-2400$ & 0.65 & Shibusawa et al. (2001) \\
OC & NIR & $1100-2500$ & 0.98 & McCarty et al. (2002) \\
OC & NIR & $700-2500$ & 0.68 & Islam et al. (2003) \\
OC & VIS-NIR & $400-1100$ & 0.86 & Dariel et al. (2003) \\
OM & VIS-NIR & $400-1190$ & 0.59 & Daniel et al. (2004) \\
OM & VIS & $400-680$ & 0.68 & Stamatiadis and Christofides (2005) \\
OM & NIR & 800 & 0.45 & Stamatiadis and Christofides (2005) \\
OC & NIR & $700-2500$ & 0,60 & Rossel et al. (2006) \\
OC & VIS & $400-700$ & 0.60 & Rossel et al. (2006) \\
OM & VIS-NIR & $450-2500$ & 0.87 & Wetterlind \\
\hline
\end{tabular}

Table 2 A review of the literature comparing quantitative predictions of soil OC or OM using multivariate analyses and spectral response in the VIS, NIR and MIR regions of the electromagnetic spectrum

Iron oxide content has been accurately predicted in the VNIR region using reflectance spectroscopy due to the characteristic absorption features of iron oxide (Ben-Dor and Banin, 1995; Chang et al., 2001; Kemper \& Sommer, 2002 ; Wu et al., 2007). The four distinct regions most commonly used for the determination of iron oxide content include 550-650,750-950, 1406 and $2449 \mathrm{~nm}$ (Ben-Dor and Banin, 1995; Ben-Dor et al., 2009). A recent study indicated that the absorption features of iron oxides at wavelengths between $400-1300 \mathrm{~nm}$ can best be used to predict iron oxide content (Summers, 2009).

The spectral features of clays are most prevalent in the NIR region where distinctive absorption bands can be used to provide quantitative information on clay mineralogy (Al-Abbas et al., 1972; Wetterlind et al., 2008) and reflectance spectroscopy, with regression modelling, has also been a commonly used technique for the prediction of total clay content (Waiser et al., 2006; Rossel et al., 2009; Summers, 2009). Chabrillat et al., (2002) also found that hyperspectral imagery can be used to reliably predict clay mineralogy at 2200 $\mu \mathrm{m}$ due to the characteristic features of the clay minerals. Similarly, Clark (1999) found that clay minerals had characteristic of absorption bands at approximately $2200 \mu \mathrm{m}$. In general, finer texture soil presents as being darker than coarse textured soils (Summers, 2009), and consequently soil with sand or silt $(>0.002 \mathrm{~mm})$ has higher spectral reflectance than clay minerals $(<0.002 \mathrm{~mm}$ ) due to the increased water (high absorption of spectra) filling capacity of clay. All of these studies confirm that VNIR spectral based techniques have the potential to accurately identify a myriad of different soils properties.

\subsection{Lead Spectroscopy}

Using spectral remote sensing methods, several direct and indirect soil contamination characteristics, can be extracted simply via regression analysis. A number of spectroscopic techniques for assessing heavy metals contamination have been identified during the last two decades (Plaza et al., 2002; Wu et al., 2007; Choe et al., 2008; Minasny et al., 2009; Pandit et al., 2010). Many researchers reported that detection and quantification of $\mathrm{Pb}$ concentrations, and other heavy metals, was possible, indirectly based on their association with other detectable materials. For example, (Malley and Williams, 1997)) applied NIRS for quantitative prediction of heavy metals reporting that $\mathrm{OM}$ was primarily responsible for predicting a range of heavy metals $(\mathrm{Cd}, \mathrm{Cu}, \mathrm{Fe}, \mathrm{Mn}, \mathrm{Ni}, \mathrm{Pb}$ and $\mathrm{Zn})$ based on multivariate regression. Schwartz et al. (2011) also suggested that soil contamination may be detected indirectly via association with moieties such as hydroxides, sulphides, carbonates, or oxides which are detectable, or adsorption to clays that absorb light in the VNIR-SWIR region. Yaolin et al. (2011) found good correlation between SOM, Pb concentration and laboratory based hyperspectral data in the range of 624-564 $\mathrm{nm}$. according to the following equations:

$\mathrm{SOM}=11.5 *$ fod $(624) /$ fod $(564)\left(\mathrm{R}^{2}=0.53\right.$, s.e. $=1.14, \mathrm{~F}=$ 18.99, $\mathrm{P}<0.001, \mathrm{df}=18)$

$\mathrm{Pb}=2.973+1.006 * \mathrm{SOM}\left(\mathrm{R}^{2}=0.59\right.$, s.e. $=1.41, \mathrm{~F}=17.05$,

$\mathrm{P}<0.001, \mathrm{df}=13$ )

They then derived $\mathrm{Pb}$ concentration via the ratio of first order derivative (fod) as shown in equation (3)

$\mathrm{Pb}=2.973+1.006 * 11.5 *$ fod $(624) /$ fod $(564)$

Moreover, there was a significant relationship between metal levels $(\mathrm{Cd}, \mathrm{Hg}, \mathrm{Pb}$, ) within the spectral domain 500-700 nm which was related to organic carbon (Bray et al., 2009; Ji et al., 2010; Pandit et al., 2010). Soil Pb contamination can also be estimated indirectly using reflectance spectroscopy via correlations with iron oxide contents. Kemper and Sommer (2002) found a strong relationship between iron and heavy metals concentrations, including $\mathrm{Pb}$, when using multiple linear regression analysis (MLR) and an artificial neural network (ANN). While $\mathrm{Wu}$ et al. (2007) found that Fe had a high correlation and high cross validation statistic with heavy metals, Vohland (2009) found a strong correlation between $\mathrm{Pb}$ and other heavy metals and Fe and clay fractions. Recent research has found a strong spectral signature for soil $\mathrm{Pb}$ content using bands selected from hyperspectral laboratory measurements where the soil spectral curve absorption values or reflectance peaks occurred at 838, 1930 and $2148 \mathrm{~nm}$ (Figure 1). However, the two spectral regions between $840-900 \mathrm{~nm}$ and $2300-2500$ $\mathrm{nm}$ were not very useful due to the weak signal (Zhang et al., 2010). In another study, when the reflectance was measured outdoors, from a transect of near-road to far-road samples (samples 1 to 8 in Figure 2) reflectance at 1400 and $1900 \mathrm{~nm}$ was removed due to noise resulting from atmospheric water content (Pandit et al., 2010). This study, which was conducted in an urban area near a heavily travelled New York street, was considered to be a stable and appropriate site to evaluate urban atmospheric deposition of contaminants from vehicular traffic. This study also assumed two things 1) an inverse relationship between $\mathrm{Pb}$ concentrations and reflectance and 2) $\mathrm{Pb}$ concentrations were a significant function of the changing spectral signatures of the soil samples. However, Wu et al. (2007) observed that heavy metal elements cannot be detected 
directly based solely on spectroscopy data if the concentrations were below $1000 \mathrm{mg} / \mathrm{kg}$. Given that most field concentrations of $\mathrm{Pb}$ are $<1000 \mathrm{mg} / \mathrm{kg}$, it is likely both direct and indirect methods will need to be employed to remotely detect the presence and concentration of $\mathrm{Pb}$. If a combination of spectral
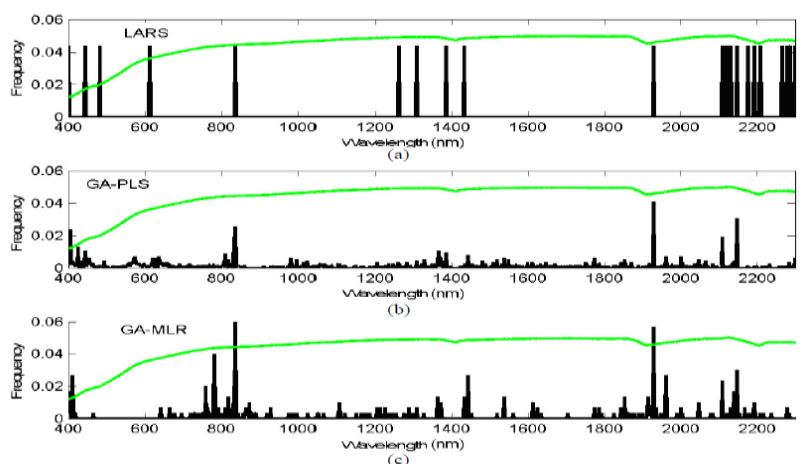

Figure 1 Comparison between three prediction methods using appropriate bands selections for the determination of soil lead content. The curve represents one typical soil reflectance spectrum (Zhang et al., 2010).

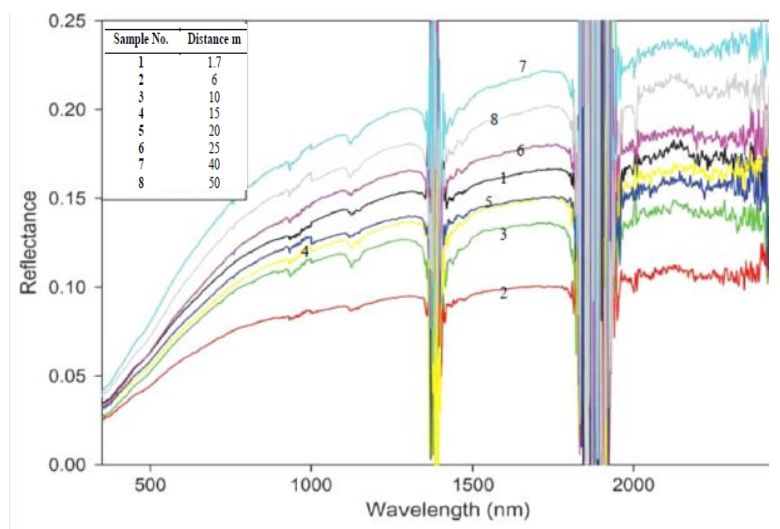

Figure 2. An illustration (Pandit et al. 2010) of the inverse relationship between the wavelength and soil $\mathrm{Pb}$ content for eight soil samples from a transect of near-road to far-road. Also, shown are the noise regions at 1400 and $1900 \mathrm{~nm}$ due to the influence of atmospheric water at outdoor reflectance measurement (Cocks et al., 1998; Pandit et al., 2010). Distances of the samples from the road are given in the inset.

techniques can be found to detect $\mathrm{Pb}$ then time and costs will be minimized, thus providing the opportunity to significantly analyse more samples over a larger spatial extent, allowing the spatial distribution patterns of contamination to more reliably be determined.

\section{MULTIVARIATE ANALYSIS FOR PB PREDICTION}

Imaging spectrometry of soil often provides contradictory estimates of soil heavy metal content depending on the data processing methods employed. Multivariate calibration of spectral information can be used to accurately predict several soil components with small root mean standard errors of cross validation (RMSECV), large correlation coefficients $\left(\mathrm{r}^{2}\right)$ and slopes close to unity for the regression of predicted and measured soil properties. While many multivariate calibration methods have been applied to relate NIR spectra with measured soil properties, the most commonly applied approaches for spectral calibration and predication include (i) partial least squares regression (PLSR), (ii) linear spectral unmixing, (iii) principal components regression (PCR), and (iv) multiple adaptive regression splines (MARS), (Kooistra et al., 2001; Wu et al., 2005c; Pandit et al., 2010). The choice of processing method is also important for accurately determining the soil $\mathrm{Pb}$ content from hyperspectral data analysis, and can improve the effective band selection (Zhang et al., 2010). However, to date none of these proposed calibration techniques have achieved universal acceptance because a calibration model that works well for one application may be unacceptable for another. This highlights the importance of validating the technique for the specific landscape under consideration prior to widespread general adoption.

\section{CONCLUSIONS AND FUTURE WORK}

This review has demonstrated that visible-near and short infrared reflectance spectra contain significant information related to soil components, including $\mathrm{Pb}$ concentrations. Thus reflectance spectroscopy has potential as a rapid, low cost technique for mapping soil contamination. However, as the spectral characteristics of soil in the spectral range from 400$2500 \mathrm{~nm}$ is extremely complex, finding spectral features attributable to $\mathrm{Pb}$ concentrations which are unaffected by the chemical composition and physical conditions at the soil surface is a significant challenge. However some studies have demonstrated that the spectral interferences between heavy metals and some spectrally active soil constituents, such as organic matter, iron oxide and clay minerals can actually be used to infer metal concentrations, and significant correlation between soil constituents and metal concentrations have been observed using hyerspectral data in the NIR and SWIR region resulting in good direct and indirect prediction of many soil properties including $\mathrm{Pb}$ contamination. Implementation of a remote sensing approach will complement existing methods for estimating $\mathrm{Pb}$ concentrations in soils and will provide powerful tools to address the specific site management.

Future research will concentrate on definitely establishing whether $\mathrm{Pb}$ contamination in soils can be assayed directly or indirectly in the VNIR and SWIR region using reflectance spectroscopy using artificially soils spiked with $\mathrm{Pb}$ in the range $50-10,000 \mathrm{ppm}$ and examination of arrange of soils from the vicinity of an active smelter in Port Pirie, South Australia. Suitable spectra will be collected using an Analytical Spectral Devices (ASD) operated between 350 and $2500 \mathrm{~nm}$ and the spectra derived $\mathrm{Pb}$ concentrations compared to actual $\mathrm{Pb}$ concentrations determined using traditional wet chemical analytical techniques.

\section{ACKNOWLEDGEMENTS}

All authors acknowledge the support of the Centre for Environmental Risk Assessment and Remediation (CERAR), the University of South Australia and the Barbara Hardy Institute, while undertaking this research. The first author gratefully acknowledges the financial support of the Iraq government, Ministry of Higher Education and Scientific Research for a PhD stipend.

\section{REFERENCES}

Al-Abbas, A. Swain, P. and Baumgardner, M., 1972. Relating organic matter and clay content to the multispectral radiance of soils. Soil Science, vol. 114, pp. 477-485. 
Ben-Dor, E. and Banin, A., 1995. Near-infrared analysis as a rapid method to simultaneously evaluate several soil properties. Soil Science Society of America Journal, 59(2), pp.364-372.

Ben-Dor, E. Patkin, K. Banin , A. and Karnieli, A., 2002. Mapping of several soil properties using DAIS-7915 hyperspectral scanner data-a case study over clayey soils in Israel. Internationa Journal of Remote Sensing, 23(6), pp. 1043-1062.

Ben-Dor, E. Chabrillat, S. Demattê, J. Taylor, G. Hill , J. Whiting, M. and Sommer, S., 2009. Using imaging spectroscopy to study soil properties. Remote Sensing of Environment, 113, pp. S38-S55.

Bilgili, A. Van Es, H. Akbas, F. Durak, A. and Hively, W., 2010. Visible-near infrared reflectance spectroscopy for assessment of soil properties in a semi-arid area of Turkey. Journal of Arid Environments, 74, pp. 229-238.

Bray, J. Rossel, R. and McBratney, A., 2009. Diagnostic screening of urban soil contaminants using diffuse reflectance spectroscopy', Australian Journal of Soil Research, 47 pp. 433442 .

Chabrillat, S. Goetza, A. Krosleyc, L. and Olsenc, H., 2002. Use of hyperspectral images in the identification and mapping of expansive clay soils and the role of spatial resolution. Remote Sensing of Environment, 82(2-3), pp. 431-445.

Chang, C. Laird, D. Mausbach, M. and Hurburgh, C., 2001. Near-infrared reflectance spectroscopy-principal components regression analyses of soil properties. Soil Science Society of America Journal, 65, pp. 480-490.

Choe, E. Meer, F. Ruitenbeek, F. Werff, H. De Smeth, B. and Kim, K., 2008. Mapping of heavy metal pollution in stream sediments using combined geochemistry, field spectroscopy, and hyperspectral remote sensing: A case study of the Rodalquilar mining area, SE Spain. Remote Sensing of Environment, 112, pp. 3222-3233.

Clark, R., 1999. Spectroscopy of Rocks and Minerals and Prenciples of Spectroscopy', in Rencz.A (ed), Remote Sensing for the Earth Sciences, Manual of Remote Sensingedn, 3, John Wiley and Sons, New York pp. 3-58.

Cocks, T, Jenssen, R, Stewart, A, Wilson, I \& Shields, T 1998, 'The HYmapTM airbornce hyperspectral sensor: the system, calibration and performance. Science, pp. 1-7.

Fox, A. and Metla, R., 2005. Soil property analysis using principal components analysis, soil line, and regression models. Soil Science Society of America Journal, 69(6), pp. 1782-1788.

Galvão, S. and Vitorello, I., 1998. Role of organic matter in obliterating the effects of iron on mspectral reflectance and colour of Brazilian tropical soils. International Journal of Remote Sensing of Environment, 19(10), pp. 1969-1979.

Garcia-Haro, F. Sommer, S. and Kemper, T., 2005. A new tool for variable multiple endmember spectral mixture analysis (VMESMA). International Journal of Remote Sensing, 26(10).

Griffith, D., 2002. The Geographic distribution of soil lead concentration:description and concerns. URISA, 14(1).
Harris, A., 2006. Spectral mapping tools from the earth sciences applied to spectral microscopy data. International Society for Analytical Cytology, 69, pp. 872-879.

Ji, J. Song, Y. Yuan, X. and Yang, Z., 2010. Diffuse reflectance spectroscopy study of heavy metals in agricultural soils of the Changjiang River Delta, China.In: 19th World Congress of Soil Science, Soil Solutions for a Changing World, Brisbane, Australia.

Kachenko, A. and Singh, B., 2006. Heavy metals contamination in vegetables grown in urban and metal smelter contaminated sites in Australia. Water,Air , and Soil Pollution, 169, pp. 101123.

Kemper, T. García-Haro, J. Preissler, H. Mehl, W. and Sommer, S., 2000. A multiple endmember unmixing approach for mapping heavy metal contamination after the Donana mining accident ( Sevilla,Spain).In: 2nd EARSeL Workshop on Imaging Spectroscopy, Ens chede.

Kemper, T. and Sommer, S., 2002. Estimate of heavy metal contamination in soils after a mining accident using reflectance spectroscopy. Environmental Science and Technology, $36 \mathrm{pp}$. 2742-2747

Kemper, T. and Sommer, S., 2003. Mapping and monitoring of residual heavy metal contamination and acidification risk after the Aznalcóllar mining accident (Andalusia, Spain) using field and airborne hyperspectral data. In: the 3rd EARSeL Workshop on Imaging Spectroscopy, Herrsching.

Kooistra, L. Wehrens, R. Leuven, R. and Buydens, L., 2001. Possibilities of visible-near-infrared spectroscopy for the assessment of soil contamination in river floodplains. Analytica Chimica Acta, 446(1-2), pp. 97-105.

Krishnan, P. Alexander, J. and Butler, B., 1980. Reflectance technique for predicting soil organic matter. Soil Science, 44(6), pp. 1282-1285.

Lu, Y. Bai, Y. and Yang, L., 2007. Prediction and validation of soil organic matter content based on hyperspectum (in Chinese). Scientia Agricultura Sinica, 40(9), pp. 1989-1995.

Malley, D. and Williams, P., 1997. Use of near-infrared reflectance spectroscopy in prediction of heavy metals in freshwater sediment by their association with organic matter. Environmental Sciance and Technology, 31(12), pp. 3461-3467.

Minasny, B. Tranter, G. McBratney, A. Brough, D. and Murphy, B., 2009. Regional transferability of mid-infrared diffuse reflectance spectroscopic prediction for soil chemical properties. Geoderma, 153, pp. 155-162.

Pandit, M. Filippelli, M. and Li, L., 2010. Estimation of heavymetal contamination in soil using reflectance spectroscopy and partial least-squares regression. International Journal of Remote Sensing, 31(15), pp. 4111-4123.

Pastor, I. Pedreño, J. Gómez, I. and Koch, M., 2008. Identifying optimal spectral bands to assess soil properties with VNIR radiometry in semi-arid soils. Geoderma, 147, pp. 126-132.

Plaza, A. Martínez, P. Pérez, R. and Plaza, J., 2002. Spatial / spectral endmember extraction by multidimensional 
morphological operations. IEEE Transactions on Geoscience and Remote Sensing, 40(9).

Rossel, R. Walvoort, D. Mcbratney, A. Janik, L. and Skjemstad, J., 2006. Visible, near infrared, mid infrared or combined diffuse reflectance spectroscopy for simultaneous assessment of various soil properties. Geoderma, 131, pp. 59-75.

Rossel, R. Cattle, S. Ortega, A. and Fouad, Y., 2009. In situ measurements of soil colour, mineral composition and clay content by vis-near spectroscopy. Geoderma, 150, pp. 253-266.

Schwartz, G. Eshel, G. and Ben-Dor, E., 2012. Reflectance Spectroscopy as a Rapid Tool for Monitoring Contaminated Soil. Porter School of environmental studies,Tel Aviv University. $\mathrm{PhD}$ thesis.

Shrestha, P., 2006. Relating soil electrical conductivity to remote sensing and other soil properties for assessing soil salinity in northeast Thailand. Land Degradation and Development, 17(6), pp. 677-689.

Summers, D., 2009. Discriminating and Mapping Soil Variability with Hyperspectral Reflectance Data. Faculty of science,School of earth and environmental science, Adelaide University. $\mathrm{PhD}$ thesis.

Vohland, M. Bossung, C. and Frund, H., 2009. A spectroscopic approach to assess trace-heavy metal contents in contaminated floodplain soils via spectrally active soil components. plant nutrition and soil science, 172(2), pp. 201-209.

Waiser, T. Morgan, C. Brown, D. and Hallmark, C., 2006. In situ characterization of soil clay content with visible nearinfrared diffuse reflectance spectroscopy. Soil Science Society of America Journal, 71 (2), pp. 389-396.

Wetterlind, J. Bo, S. and Jonsson, A., 2008. Near infrared reflectance spectroscopy compared with soil clay and organic matter content for estimating within-field variation in $\mathrm{N}$ uptake in cereals. Plant and Soil, 302(1-2), pp. 317-327.

WHO. 2010. Exposure to lead: a major public health conern. World Health Organization, Geneva, Switzerland.

Winkelmann, H., 2005. On the Applicability of Imaging Spectrometry for the Detection and Investigation of Contaminated Sites with Particular Consideration Given to the Detection of Fuel Hydrocarbon Contaminants in Soil. Faculty of Environmental Sciences and Process Engineering, Brandenburg University of Technology. PhD thesis.

Wu, Y. Chen, J. J I, J. Tian, Q. and Wu, X., 2005a. Feasibility of reflectance spectroscopy for the assessment of soil mercury contamination. Environmental Science and Technology, 39(3), pp. 873-878.

Wu, Y. Chen, J. Wu, X. Tian, Q. J I, J. and Qin, Z., 2005b. Possibilities of reflectance spectroscopy for the assessment of contaminant elements in suburban soils. Applied Geochemistry, 20(6), pp. 1051-1059.

Wu, Y. Chen, J. Ji, J. Gong, P. Liao, Q. Tian, Q. and Ma, H., 2007. A Mechanism study of reflectance spectroscopy for investigating heavy metals in soil. Soil Science Society of America Journal, 17.
Yaolin, L. Wei, L. Guofeng, W. and Xinguo, X., 2011. Feasibility of estimating heavy metal contaminations in floodplain soils using laboratory-based hyperspectral data-a case study along Le'an River, China. Geo-spatial Information Science, 14(1).

Zhang, Z. Wen, J. and Zhao, D., 2010. Band selection method for retrieving soil lead content with hyperspectral remote sensing data. The Society of Photo-Optical Instrumentation Engineers (SPIE), 7831, 2010. 